\title{
Pendampingan dalam Mewujudkan Budaya Tertib Arsip Informasi KTP dan KK di Kantor Kelurahan Pulau Abang, Provinsi Kepulauan Riau
}

\section{Assistance in Supporting Well Culture of KTP and KK information archiving at Pulau Abang Sub-district office, Kepulauan Riau Province}

\author{
Syamsir Hasibuan ${ }^{1}$, Amrullah Rasal ${ }^{2}$, Erwin Ashari ${ }^{3}$, dan Ramses ${ }^{4}$ \\ Ilmu Hukum, Fakultas Hukum, Universitas Riau Kepulauan, Indonesia \\ Ilmu Pemerintahan, Fakultas Sosial Politik, Universitas Riau Kepulauan, Indonesia \\ Pendidikan Bahasa Inggris, FKIP, Universitas Riau Kepulauan, Indonesia \\ Pendidikan Biologi, FKIP, Universitas Riau Kepulauan, Indonesia \\ Coresponding; erwinashariharianja83@gmail.com
}

\begin{abstract}
Abstrak
Tujuan dari kegiatan ini adalah melakukan pendampingan dan penataan pearsipan informasi kartu tanda penduduk (KTP) dan Kartu Keluarga (KK) di kantor Kelurahan Pulau Abang agar terwujud budaya tertib arsip sesuai dengan yang tercantum dalam Undang-Undang Nomor 43 Pasal 1 dan Ayat 2 Tahun 2009 Tentang Kearsipan. Lokasi kegiatan ini adalah kelurahan Pulau Abang yang berpenduduk 478 kartu keluarga yang meliputi 3 wilayah kampung yang berpenduduk yaitu Pulau Abang Kecilyang memiliki sekitar 260 kartu keluarga, Air Saga yang memiliki 120 kartu keluarga dan Pulau Petong dengan 98 kartu keluarga. Adapun metode yang dilakukan dalam kegiatan ini adalah dengan menggunakan metode observasi, interview dan studi pustaka melalui penerapan pendekatan pengarsipan secara abjad.Kegiatan ini dilakukan selama tiga hari yakni mulai tanggal 5 sampai dengan 7 Agustus 2019. Adapun hasil dari kegiatan ini adalah; tersususunnya arsip KTP dan KK di kantor Kelurahan Pulau Abang berdasarkan abjad nama kepala keluarga pada setiap RT di wilayah kampung di kelurahan Pulau Abang. Adapun masing-masingKTP disatukan atau difilekan pada KK masingmasing.Kondisi seperti sangat membantu pemerintahan kelurahan Pulau Abang dalam melaksanakan tugas pokoknya khususnya dalam pencatatatan kependudukan secara efisien dan efektif.
\end{abstract}

Kata kunci; Tertib Arsip, Pengarsipan Secara Abjad, Pulau Abang.

\begin{abstract}
The purpose of this activity is to assist and organize KTP and KK information archiving at Pulau Abang Subdistrict office, Kepulauan Riau Province in order to create anwell culture of archives in accordance to which stated in the Law Number 43 Article 1 and Paragraph 2 of 2009 concerning Archives. The location of this activity was at Pulau Abang Sub-district office, Kepulauan Riau Province with 478 KK covering 3 inhabited village areas, Pulau Abang Kecil which has around 260 KK, Air Saga which has 120 KK and Pulau Petong with $98 \mathrm{KK}$. The method used in this activity was to use the method of observation, interview and literature study through the application of the alphabetical archiving approach. This activity was carried out for three days, from 5 to 7 August 2019. The results of this activity are; the compilation of KTP and KK archives at Pulau Abang Sub-district officealphabeticallybased on the family name in each neighborhood atPulau Abang Sub-district. Each KTP is put together or filtered on each KK. Such conditions are very helpful for tPulau Abang Sub-district administrators in carrying out their main tasks, especially in recording population efficiently and effectively.
\end{abstract}

Keywords; well Archives, Archiving Alphabetically, Pulau Abang. 


\section{PENDAHULUAN}

Dengan berkembangnya ilmu dan teknologimemberikan dampak positif terhadap terhadap seluruh kegiatan yang dilakukan oleh individu, organisasi, maupun pemerintah. Rekaman informasi-informasi yang menjaji jejak dari individu, organisasi, maupun pemerintah perlu dikelola dengan baik sehingga bias dijadikan sebagai bahan kajian evaluasi untuk perbaikan kedepannya, dengan kata lain perlu dilakukan pengarsipan yang baik agar semua informasi bisa terekam dengan baik. Seperti yang diketahui Undang-Undang Republik Indonesia Nomor 43 Pasal 1 dan Ayat 2 Tahun 2009 Tentang Kearsipan yaitu Arsip adalah rekaman kegiatan atau peristiwa dalam berbagai bentuk dan media sesuai dengan perkembangan teknologi informasi dan komunikasi yang dibuat dan diterima oleh lembaga negara, pemerintahan daerah, lembaga pendidikan, perusahaan, organisasi politik, organisasi kemasyarakatan, dan perseorangan dalam pelaksanaan kehidupan bermasyarakat, berbangsa, dan bernegara.

Arsip mengandung berbagai informasi berharga bagi lembaga yang mengeluarkannya,.Tujuan manajemen arsip adalah unutk menyatukaninformasi, memudahkan akses dan penemuan kembali informasi, mengamankan arsip, meningkatkan pemanfaatan dan pendayagunaan arsip (Damalita, 2009). Dengan menyimpan data arsip maka dapat digunakan kapan saja dan dirancang agar dapat memberikan informasi kearsipan dengan lengkap(Irmawati \& Indrihapsari, 2014), sehingga dapat meminimalisir kesalahan manajemen yang akan diambil oleh organisasi pemerintah maupun swasta melalui tersedianya informasi yang tersaji dengan baik dan benar(Sibali, 2010). Dari hal tersebut maka diharapkan agar setiap pemerintah daerah memiliki kearsipan yang baik dan transparan, mulai dari pusat hingga ke daerah, termasuk di kelurahan .

Salah satu kelurahan yang ada di Kota batam adalah kelurahan, Pulau Abang sendiri merupakan pulau kecil yang berada di sebelah selatan kota Batam, provinsi Kepulauan Riau. Pulau Abang merupakanwilayah yang di kelilingi oleh pulau-pulau wisata dengan jumlah penduduk 478 kartu keluarga yang meliputi 3 desa yaitu Pulau Abang Besar yang memiliki sekitar 260 kartu keluarga, Air Saga yang memiliki 120 kartu keluarga dan Pulau Petong 

sebagai nelayan.

Pulau Abang sendiri masuk ke dalam Gugusan Kepulauan Riau yang memiliki 42 pulau antara lain Pulau Abang Besar, Pulau Abang Kecil, Petong, Galang Baru, Nguan, Teleje, Penggelap, Pasir Bukul dan gugusan pulau-pulau kecil lainnya (Sachoemar \& Aliah : 2010). Menurut (Sachoemar \& Aliah : 2010) sesuai dengan Rencana Umum Tata Ruang Wilayah (RUTRW) Kota Batam, kawasan Pulau Abang akan dijadikan sebagai kawasan budidaya laut dan pariwisata. Pulau Abang memang pulau yang tepat untuk dijadikan tempat pariwisata karena Pulau Abang memiliki perairan yang jernih dengan lautan birunya yang indah.Selain itu di perairan Pulau Abang juga memiliki terumbu karang dan berbagai jenis ikan hias yang berwarna-warni.

Sebagai salah satu daerah wisata Bahari, Pulau Abang seharusnya memiliki administrasi yang baik dan berfasilitas lengkap, kinerja dan pertanggung jawaban yang baik, namun pada kenyataannya terdapatmasalah dalam pendataan dan administrasi di pulau Abang yang terbilang masih buruk terutama dalam hal pengarsipan, seharusnya pengolahan kerasipan yang meliputi pencatatan, penyimpanan, pemeliharaan, pemindahan dan pemusnahan arsip(Sanora, 2016) sebab ketahanan arsip tersebut akan sangat bergantung terhadap pengelolaan maupun tindakan preservasi yang dilakukan sepanjang siklus hidup arsip itu sendiri (Nufus, 2017). Dengan melaksanakan sistem penyimpanan arsip yang disimpan oleh masing-masing bagian yang sesuai dengan bidangnya, maka apabila arsip tersebut diperlukan sewaktu-waktu dapat ditemukan dengan cepat dan tepat(Tusianasari, 2011)(Smk, Padang, \& Sumatera, 2016)(Mufidah, 2013), hal ini dapat menunjang produktivitas dan keefisienan kerja pegawai(S \& Sutarni, 2017). Namun pada kenyataannnya Pengarsipan data penduduk di pulau Abang tidak dikelola secara baik, dokumen tidak tersusun rapi sehingga memberikan kesulitan untuk mencari data penduduk. Selain itu,penyusunan berkas KK dan KTP yang tidak sesuai dengan syarat pengarsipan.Seperti masalah-masalah yang sering dijumpai di berbagai administrasi lainnya, masalah kearsipan yang terjadi dipulau Abang termasuk suatu hal yang harus diberikan solusi.

1. Pengolahan klasifikasi yang salah 
2. Tidak ada waktu dan perencanaan untuk penyimpanan data seperti Kartu Keluarga dan Kartu Tanda Penduduk

3. Ruang dan perlengkapan tidak sesuai dengan data

4. Peralatan penyimpanan tidak memenuhi syarat

Dalam mengelola sebuah arsip, tidak hanya prosedur yang perlu diperhatikan, namun juga didukung oleh pegawai yang bekerja pada unit kearsipan, sarana atau fasilitas yang dipergunakan dan dana yang tersedia untuk pemeliharaan arsip.Masalah ketidak tahuan staf yang membuat arsip di pulau abang terbengkalai, masalah arsip dan ketidak tahuan staf kelurahan seharusnya tidak boleh berlanjut. Dari masalah yang ada maka akan berakibat pada hal-hal sebagai berikut; tidak dapat menemukan kembali arsip secara cepat suatu surat yang diperlukan leh atasan atau petugas unit lain dari bagian arsip, serta peminjaman atau pemakaian suatu surat oleh unit lain dala waktu lama, bahkan kadang-kadang tidak dikembalikan.Melihat kondisi di kelurahan yang dimana arsip tidak sesuai dengan syarat undang-undang kewajiban kearsipan maka dengan demikian, bagian koordinasi lapangan dibidang kelurahan melakukan pengarsipan dimana data KK dan KTP di arsipkan sesuai dengan Undang - Undang Nomor 7 Tahun 1971 Tentang Ketentuan-Ketentuan Pokok Kearsipan dengan mempertimbangkan 3 sistem yakni sistem abjad, wilayah dan masalah.

Pada sistem penyimpanan atau pengarsipan abjad, ini merupakan salah satu sistem penataan berkas yang menggunakan metode penyusunan berdasarkan abjad secara berurutan dari A sampai dengan $\mathrm{Z}$ dengan berpedoman pada peraturan mengindeks. Sistem penyimpanan arsip wilayah atau geografis adalah suatu sistem penyimpanan arsip berdasarkan pembagian wilayah atau daerahyang terbagi menjadi 3 desa, Sistem subjek merupakan suatu sistem penyimpanan arsip berdasarkan masalah dimana surat-surat dikelompokkan kedalam daftar indeks untuk ditentukan masalah-masalah yang pada umumnya terjadi, terutama pembuatan KTP sesuai dengan domisili, ppembuatan KK baru dan surat keterangan pindah.Dengan demikian setelah dilakukan pengarsipan maka pihak kelurahan dapat dengan mudah mencari data dan penyimpanan yang rapi membuat data menjadi tahan lebih lama serta staf kelurahan memiliki pertanggungjawaban pribadi terhadap informasi pribadi masyarakat. 


\section{METODOLOGI}

Pendampingan ini dilakukan di Kantor Kelurahan Pulau Abang selama lima (5) hari yakni pada tanggal 3 Agustus 2019 sampai dengan 7 Agustus 2019. Dalam pendampingan ini, dilaksanakan pada hari efektif dan dengan melibatkan semua staff kelurahan Pulau Abang. Adapun metode yang dilakukan dalam pendampinganini adalah dengan menggunakan metode observasi, interview dan studi pustaka. Metode Observasi dilakukan untuk mengetahui kondisi awal pengarsipan yang ada di kantor Kelurahan Pulau Abang. Dalam proses ini, pihak kelurahan ikut terlibat langsung dan memberika informasi lisan selama tim melakukan observasi di kantor kelurahan. Dalam observasi ini, tim juga melakukan interview langsung dengan pimpinan dalam hal ini Sekretaris kelurahan Pulau Abang serta staff tentang kondisi pengarsipan di kantor kelurahan Pulau Abang. Setelah informasi didapatkan, maka tim melakukan pencarian dan penyesuaian dengan referensi yang ada berupa bersumber dari Undang-undang, buku dan jurnal yang ada, sehingga hasil dari pendampinganini bisa mencapai standar pengarsipan yang berstandar nasional.

Adapun langkah-langkah yang dilakukan dalam penanganan permasalahan dalam pendampingan ini adalah sebagai berikut;

1. Memilah setiap berkas KK dan KTP berdasarkan desa yang ada di kelurahan Pulau Abang

2. Memilah setiap berkas KK dan KTP berdasarkan RW dan RT di setiap desa yang ada di kelurahan Pulau Abang

3. Menyatukan KTP pada berkas KK setiap keluarga di setiap RT di setiap desa yang ada di kelurahan Pulau Abang yang disusun berdasarkan abjad.

4. Menyusun berkas setiap keluarga (KTP dan KK) di dalam folder per RT di setiap desa yang ada di kelurahan Pulau Abang

\section{PEMBAHASAN}

Kearsipan atau filling system merupakan suatu rangkaian kerja yang teratur, mulai dari proses penciptaan, penerimaan, pengumpulan, pengaturan, pengendalian, pemeliharaan 
Doi 10.33373/jmb.v4i1.2336

Minda Baharu, Volume 4, No 1 September 2020

P-ISSN 2656-0631; E-ISSN 2614-5944

https://www.journal.unrika.ac.id/index.php/MNDBHRU

Hal. 20-31

dan perawatan serta penyimpanan suatu dokumen menurut sistem tertentu sehingga saat diperlukan arsip tersebut dapat ditemukan dengan cepat dan tepat. Arsip merujuk pada dokumen yang memberikan informasi mengenai pelaksanaan berbagai kegiatan organisasi, kebijakan, keputusan, prosedur, operasi, dan kegiatan lainnya

Pengarsipan yang dilakukan ialah menyusun berkas di kelurahan yang berupa berkas KK dan KTP penduduk kelurahan Pulau Abang yang terdiri dari 3 desa dari 478 KK.Pengarsipan ini dibantu oleh staff administrasi kelurahan yang memberikan ruang untuk kami menyusun pengarsipan, staff adminitrasi juga memberikan sarana peralatan seperti stapler, ordner dan pembolong kertas serta mereka memberikan pengarahan tentang letak wilayah dan penyimpanan arsip.Pengarsipan ini diharapkan dapat membantu staf kelurahan dan masyarakat dalam mempermudah mencari berkas mereka terutama KK dan KTP yang telah diarsipkan sesuai dengan syarat pengarsipan agar datadapat tersimpan dengan baik.
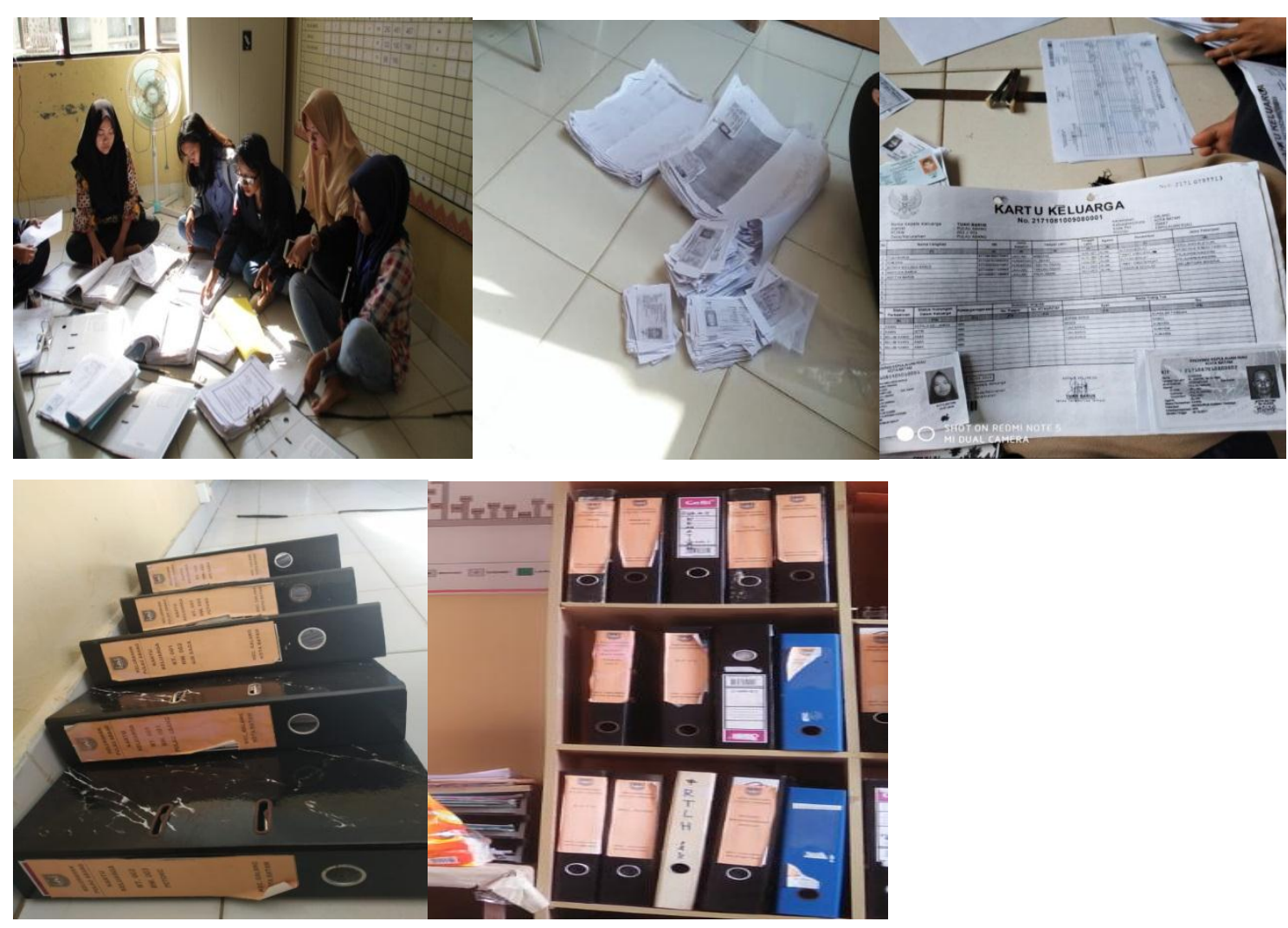

Figur 1.Alur Proses Penyusunan Arsip di Kantor Kelurahan Pulau Abang 
Minda Baharu, Volume 4, No 1 September 2020

Doi 10.33373/jmb.v4i1.2336

https://www.journal.unrika.ac.id/index.php/MNDBHRU

Arsip KK dan KTP RT 001 Pulau Abang

Hari pertama pengarsipan kami membagi KTP sesuai dengan abjad, terutama KTP yang warganya berasal dari RT 001 Pulau Abang, setelah menyusun KTP sesuai abjad kami mencari KK dan menyamakan KTP sesuai dengan nama keluarga yang tertera di KK kemudian memisahkan berkas KK dan KTP di setiap keluarga yang telah lengkap, tidak lengkap dan kurang lengkap.

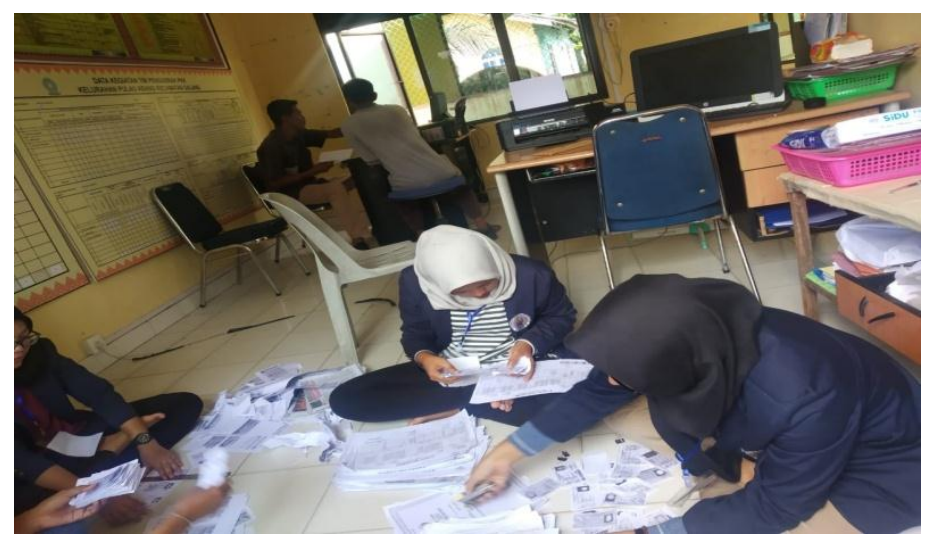

Figur 2. Menyusun Arsip KK dan KTP RT 001

\section{Arsip KK dan KTP RT 002 Pulau Abang}

Seperti RT 001 Pulau Abang, pengarsipan kami membagi KTP sesuai dengan abjad, terutama KTP yang warganya berasal dari RT 002 Pulau Abang, staff adminitrasi kelurahan memberikan peralatan pengarsipan dan ruang kami untuk mengarsip, setelah menyusun KTP sesuai abjad kami mencari KK dan menyamakan KTP sesuai dengan nama keluarga yang tertera di KK kemudian memisahkan berkas KK yang KTP di setiap keluarga telah lengkap, tidak lengkap dan kurang lengkap. 


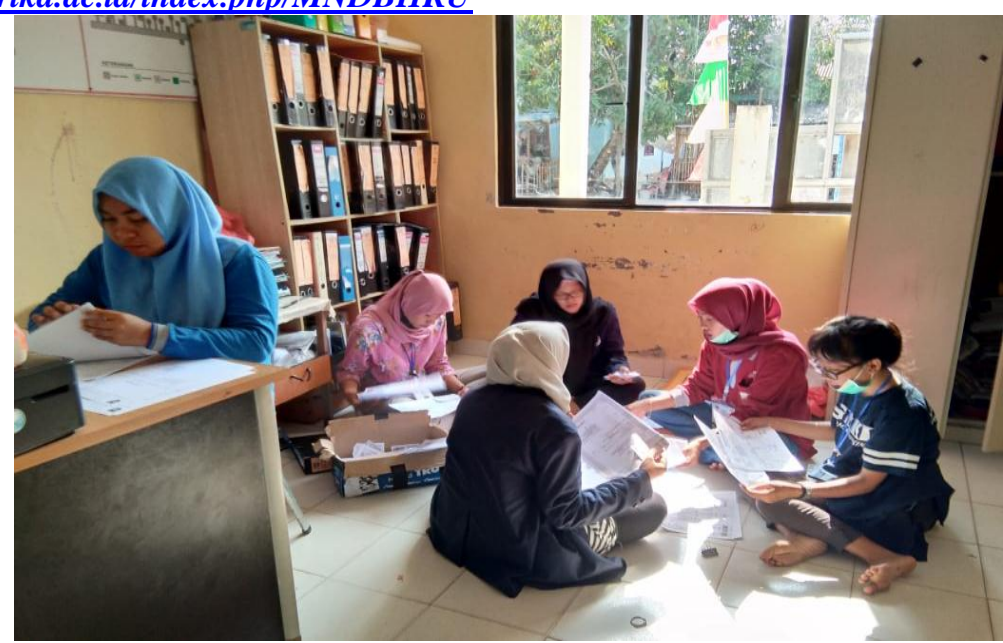

Hal. 20-31

Figur 3. Menyusun Arsip KK dan KTP RT 002

\section{$\checkmark$ Arsip KK dan KTP RT 003 Pulau Abang}

Persiapan awal membagi KTP sesuai dengan abjad, terutama KTP yang warganya berasal dari RT 003 Pulau Abang, staff adminitrasi kelurahan memberikan perlatan pengarsipan dan ruang kami untuk mengarsip, setelah menyusun KTP sesuai abjad kami mencari KK dan menyamakan KTP sesuai dengan nama keluarga yang tertera di KK kemudian memisahkan berkas KK yang KTP di setiap keluarga telah lengkap, tidak lengkap dan kurang lengkap.

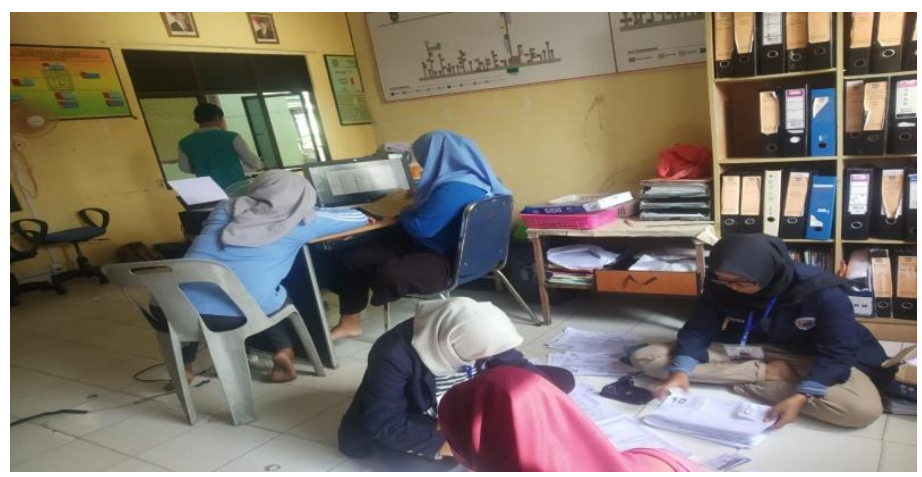

Figur 4. Menyusun Arsip KK dan KTP RT 003

Arsip KK dan KTP RT 004 Pulau Abang

Persiapan awal membagi KTP sesuai dengan abjad, terutama KTP yang warganya berasal dari RT 004 Pulau Abang, staff administrasi kelurahan memberikan perlatan 
Doi 10.33373/jmb.v4i1.2336

Minda Baharu, Volume 4, No 1 September 2020

P-ISSN 2656-0631; E-ISSN 2614-5944

https://www.journal.unrika.ac.id/index.php/MNDBHRU

Hal. 20-31

pengarsipan dan ruang kami untuk mengarsip, setelah menyusun KTP sesuai abjad kami mencari KK dan menyamakan KTP sesuai dengan nama keluarga yang tertera di KK kemudian memisahkan berkas KK yang KTP di setiap keluarga telah lengkap, tidak lengkap dan kurang lengkap.

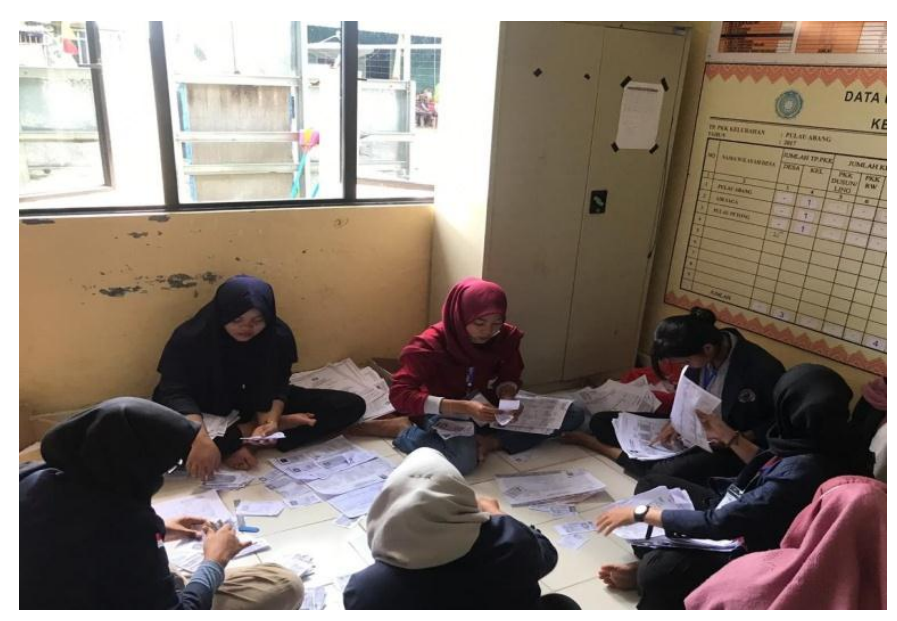

Figur 5. Menyusun Arsip KK dan KTP RT 004

\section{$\checkmark \quad$ Arsip KK dan KTP RT 001 Air Saga}

Persiapan awal membagi KTP sesuai dengan abjad, terutama KTP yang warganya berasal dari RT 001 Air Saga, staff administrasi kelurahan memberikan perlatan pengarsipan dan ruang kami untuk mengarsip, setelah menyusun KTP sesuai abjad kami mencari KK dan menyamakan KTP sesuai dengan nama keluarga yang tertera di KK kemudian memisahkan berkas KK yang KTP di setiap keluarga telah lengkap, tidak lengkap dan kurang lengkap.

$\checkmark$ Arsip KK dan KTP RT 002 Air Saga

Persiapan awal membagi KTP sesuai dengan abjad, terutama KTP yang warganya berasal dari RT 002 Air Saga, staf adminitrasi kelurahan memberikan perlatan pengarsipan dan ruang kami untuk mengarsip, setelah menyusun KTP sesuai abjad kami mencari KK dan menyamakan KTP sesuai dengan nama keluarga yang tertera di KK kemudian memisahkan berkas KK yang KTP di setiap keluarga telah lengkap, tidak lengkap dan kurang lengkap.

$\checkmark \quad$ Arsip KK dan KTP RT 001 Pulau Petong

Persiapan awal membagi KTP sesuai dengan abjad, terutama KTP yang warganya berasal dari RT 001 Pulau Petong staf adminitrasi kelurahan memberikan perlatan pengarsipan dan ruang kami untuk mengarsip, setelah menyusun KTP sesuai abjad kami 
mencari KK dan menyamakan KTP sesuai dengan nama keluarga yang tertera di KK kemudian memisahkan berkas KK yang KTP di setiap keluarga telah lengkap, tidak lengkap dan kurang lengkap.

\section{$\checkmark$ Arsip KK dan KTP RT 002 Pulau Petong}

Persiapan awal membagi KTP sesuai dengan abjad, terutama KTP yang warganya berasal dari RT 002 Pulau Petong staf adminitrasi kelurahan memberikan perlatan pengarsipan dan ruang kami untuk mengarsip, setelah menyusun KTP sesuai abjad kami mencari KK dan menyamakan KTP sesuai dengan nama keluarga yang tertera di KK kemudian memisahkan berkas KK yang KTP di setiap keluarga telah lengkap, tidak lengkap dan kurang lengkap.

Dalam bidang pengarsipan, kelompok telah membuat arsip sesuai dengan KK telah di sesuaikan dengan KTP, kami membagia KK dalam 8 arsip sesuai 8 RT dari 3 Desa Di Pulau Abang. KK dan KTP sesuai dengan abjad dan desa tempat tinggal penduduk sesuai dengan data dari pemerintah dapat di gunakan sebagai penanggungjawaban atas pengelolaan suatu data . Dalam pengelolaan pengarsipan KK dan KTP di Kelurahan Pulau Abang berjalan dengan baik dan telah menyelesaikan sesuai dengan abjad, dan untuk penyimpanan berkas serta perawatan berkas yang telah ada cukup baik dijaga sehingga dapat memudahkan pegawai dalam menemukan berkas jika membutuhkan berkas tersebut. Jikalau dibandingkan dengan pengarsipan sebelumnya, maka keadaan arsip sekarang lebih terjaga dan tersususun dengan baik, maka hal ini akan mempermudah staff kelurahan dalam menemukan berkas dan dokumen yang dibutuhkan kapan saja, selain itu akan membatu dalam pendataan masyarakat.Manajemen pengarsipan sangat dibutuhkan, sebab itu merupakan bagian dari administrasi yang sangat diperlukan sehingga informasi tentang masyarakat bias terdata dengan baik. Pendataan yang baik merupakan sebagai suatu informasi pemerintah daerah maupun pusat dalam merencanakan program yang bersifat urgen dan berkala.

\section{KESIMPULAN DAN SARAN}

Arsip adalah rekaman kegiatan atau peristiwa dalam berbagai bentuk dan media sesuai dengan perkembangan teknologi informasi dan komunikasi yang dibuat dan diterima 
oleh lembaga negara, pemerintahan daerah, lembaga pendidikan, perusahaan, organisasi politik, organisasi kemasyarakatan, dan perseorangan dalam pelaksanaan kehidupan bermasyarakat, berbangsa, dan bernegara. Arsip sangat penting bagi sebuah lembaga pemerintah oleh sebab itu maka perlu melakuakan pengarsipan guna menjamin keselamatan penanggungjawaban data masyarakat dari kelurahan Pulau Abang. serta mempermudah masyarakat dan staf kelurahan mencari data dengan cepat dan berkas dapat awet terjaga.Perlunya perhatian dan pengawasan yang lebih maksimal dari Lurah terhadap pekerjaan pegawainya, sehingga pegawai dapat bekerja sebaik mungkin dan sesuai dengan peraturan, selain itu dalam proses pengelolaan kearsipan hendaknya dapat mengawasi setiap arsip yang dipakai atau dibutuhkan oleh pegawai yang membutuhkan.

\section{REFERENSI}

Damalita, S. (2009). Pentingnya Manajemen Arsip di Lingkungan Perguruan Tinggi. Jurnal Ekonomi, Manajemen Dan Bisnis (EMAS), 3(1), 1-10.

Irmawati, D., \& Indrihapsari, Y. (2014). Sistem Informasi Kearsipan Untuk Meningkatkan. Jurnal Pendidikan Teknologi Dan Kejuruan, 22(2), 136-147.

Mufidah, Y. A. (2013). Efektivitas Kerja Pegawai Dalam Penggunaan Sistem Kearsipan Elektronik Di Kantor Badan Arsip Dan Perpustakaan Kota Surabaya. Skripsi. Prodi Pendidikan Administrasi Perkantoran, Jurusan Pendidikan Ekonomi, Fakultas Ekonomi, Universitas Negeri Surabaya.

Nufus, A. (2017). Preservasi Arsip. LIBRIA, 9(2), 211-226.

S, D. N. N., \& Sutarni, N. (2017). Penerapan Sistem Kearsipan Elektronik sebagai Determinan terhadap Produktivitas Kerja Pegawai. Jurnal Pendidikan Manajemen Perkantoran, 2(2), 40-48.

Sachoemar, S. I., \& Aliah, R. S. (2010). Evaluasi Kondisi Lingkungan Perairan Kawasan Pulau Abang, Galang Baru, Batam Berdasarkan Analisa Indeks Storet dan Similaritas Canbera. JRL, 6(1), 71-78.

Sanora, N. A. (2016). Pengelolaan Arsip Pada Bagian Tata Usaha Biro Umum Kantor Gubernur Provinsi Kalimantan Timur. EJournal Administrasi Negara, 4(2), 4042-4056.

Sibali, H. M. N. D. (2010). Penerapan Sistem Kearsipan Pada Kantor Arsip Daerah 
Minda Baharu, Volume 4, No 1 September 2020

Doi 10.33373/jmb.v4i1.2336

https://www.journal.unrika.ac.id/index.php/MNDBHRU

P-ISSN 2656-0631; E-ISSN 2614-5944

Kabupaten Kutai Barat. Jurnal Eksis, 6(2), 1571-1578.

Hal. 20-31

Smk, D. I., Padang, N., \& Sumatera, P. (2016). Sistem Informasi Manajemen Kearsipan Di SMK Negeri 5 Padang Provinsi Sumatera Barat Issn: Jurnal Voteknika, 4(2), 57-69.

Tusianasari, K. (2011). Analisis sistem Kearsipan di Kantor Kecamatan Gunungpati. Skripsi.Jurusan Pendidikan Ekonomi Fakultas Ekonomi Universitas Negeri Semarang. 